\title{
Peroxisome proliferator-activated receptor $\beta$ activation promotes myonuclear accretion in skeletal muscle of adult and aged mice
}

\author{
C. Giordano • A. S. Rousseau • N. Wagner • C. Gaudel • \\ J. Murdaca • C. Jehl-Piétri • B. Sibille • P. A. Grimaldi • \\ P. Lopez
}

Received: 13 February 2009/Revised: 1 April 2009/Accepted: 21 April 2009/Published online: 5 May 2009

(C) The Author(s) 2009. This article is published with open access at Springerlink.com

\begin{abstract}
We reported recently that peroxisome proliferatoractivated receptor $\beta$ (PPAR $\beta)$ activation promotes a calcineurin-dependent exercise-like remodelling characterised by increased numbers of oxidative fibres and capillaries. As physical exercise also induces myonuclear accretion, we investigated whether PPAR $\beta$ activation alters myonuclear density. Transgenic muscle-specific PPAR $\beta$ over-expression induced $14 \%$ increase of myonuclear density. Pharmacological PPAR $\beta$ activation promoted rapid and massive myonuclear accretion ( $20 \%$ increase after $48 \mathrm{~h}$ ), which is dependent upon calcineurin/nuclear factor of activated T cells signalling pathway. In vivo bromodeoxyuridine labelling and proliferating cell nuclear antigen immunodetection revealed that PPAR $\beta$ activation did not promote cell proliferation, suggesting that the PPAR $\beta$-promoted myonuclear accretion involves fusion of pre-existing muscle precursor cells to myofibres rather than cell division. Finally, we showed that in skeletal muscle, ageing led to a down-regulation of PPAR $\beta$ accompanied by decrease of both oxidative fibre number and myonuclear density. PPAR $\beta$ pharmacological activation counteracts, at least in part, the ageing-driven muscle remodelling.
\end{abstract}

C. Giordano · A. S. Rousseau • N. Wagner · C. Gaudel •

J. Murdaca $\cdot$ C. Jehl-Piétri • B. Sibille · P. A. Grimaldi •

P. Lopez $(\bowtie)$

INSERM U907,

Université de Nice-Sophia Antipolis, Faculté de Médecine,

28 avenue de Valombrose,

06107 Nice, France

e-mail: Pascal.LOPEZ@unice.fr
Keywords Skeletal muscle fibre $\cdot$ Myoblasts $\cdot$ Myogenic response $\cdot$ Muscle plasticity $\cdot$ Calcineurin

\section{Introduction}

Adult skeletal muscle displays a remarkable capacity for regeneration and adaptation. Skeletal myofibres represent the largest cells in the body. They are syncitial, post-mitotic and terminally differentiated $[6,13,37]$. Muscle fibres are unable to proliferate but contain a pool of muscle precursor cells (MPCs), commonly called "satellite cells", which reside between the basal lamina and the sarcolemma [19]. The term of muscle precursor cells is used in this report due to the heterogeneity within the satellite cell population [40].

MPCs play crucial roles in muscle physiology, particularly in muscle repair and regeneration. In response to stress-induced myofibre damages, reparation results from the fusion of MPCs with damaged but viable myofibres $[25,27,28]$ and regeneration from the fusion of several MPCs within the basal lamina of the destroyed fibres for de novo myofibre formation [25, 31, 33, 44]. MPCs proliferation is a preliminary and obligatory step of these processes [26].

MPCs are also involved in adaptive response of skeletal muscle to acute and chronic changes in intensity or type of physical activity, such as muscle functional overload, treadmill running, chronic motor nerve stimulation or voluntary running $[2,16,30,32]$. In these particular conditions, MPCs proliferation is required for modifications of myonuclear density and myofibre hypertrophy but does not seem to be necessary for fibre twitch from faster to slower phenotype [16, 29]. However, myonuclear accretion is an early event of the adaptive response to aerobic training 
which is characterised by a transition from glycolytic to oxidative fibres. Furthermore, Tseng et al. showed that slow fibres always had small volume/myonucleus regarding to fibre diameter and that fast/oxidative fibres with high succinate dehydrogenase (SDH) activity appeared to have lower volume/myonucleus than fast/glycolytic fibres [39]. These differences in nuclear domain size between fibre types were proposed to be related to the greater amount of proteins required for oxidative metabolism, including those implicated in mitochondrial structure and functions.

Finally, the role of MPCs in age-related muscle atrophy is poorly documented, and conflicting observations have been reported. It seems that ageing does not affect the ability of MPCs to respond to various challenges even if there might exist a delay in the proliferative responses of MPCs from aged muscle [12]. Brack et al. reported that in large fast muscle fibres, the decrease of myonuclei per muscle unit preceded muscle atrophy. Authors proposed that the age-related decrease in myofibre size may actually be a compensatory response to an inadequate capacity for myonuclear replacement [4]. Bruusgaard et al. reported that aged mice display a reduction of muscle size as well as a reduction in myonuclear number [5]. In aged mouse muscles, authors have visualised many fragmented nuclei suggesting increased apoptosis and have proposed that reduction of myonuclei in old muscle could result in a reduction of regenerative capacity of MPCs [5]. This hypothesis is in contrast with previous observations made in muscle inactivity experiments, in which fibre size reduction precedes the decrease in myonuclei number [45].

We previously described the effect of peroxisome proliferator-activated receptor (PPAR $\beta$ ) over-expression or pharmacological activation in mouse tibialis anterior (TLA), a fast/oxidative-glycolytic muscle [10, 17]. In both models, we reported an impressive muscle remodelling characterised by $37 \%$ hyperplasia and an increase in oxidative fibre and capillary number [10, 18]. In PPAR $\beta$ agonist-treated animals, this remodelling takes place within only 2 days [10]. Because of the observed oxidative and angiogenic remodelling as well as the improvement of metabolic profiles of PPAR $\beta$ agonist-treated animals and humans $[15,21,36,41]$, it was proposed that activation of the PPAR $\beta$ pathway mimics, at least partially, the adaptive response of muscle to aerobic training. Muscle hyperplasia is indicative of MPC activation [14]. Furthermore, we have actually reported an increase of Myf5 and MyoD1 proteins immediately after pharmacological PPAR $\beta$ activation using GW0742, also suggesting the possible activation of MPCs [10].

As physical exercise and ageing are two physiological situations affecting myonuclear densities, we asked how PPAR $\beta$ over-expression or pharmacological activation affects myonuclear number in the TLA muscle from young and aged mice. Furthermore, we investigated whether or not MPC proliferation was required. We report here a new striking phenotype for both PPAR $\beta$ over-expressing and PPAR $\beta$ agonist-treated mice. In both cases, the number of nuclei per unit of fibre length is significantly increased. This augmentation of myonuclear density follows the same kinetic as the previously described muscle oxidative and angiogenic remodelling induced by PPAR $\beta$ pharmacological activation, starting at day 1 and being completed at day 2 of treatment [10]. Interestingly, myonuclear accretion does not require cell proliferation. As previously described for other PPAR $\beta$-dependent remodelling [10], the increase in myonuclear density is prevented by inhibition of the calcineurin pathway. Finally, we show that PPAR $\beta$ is down-regulated in aged mouse muscles and that pharmacological PPAR $\beta$ activation, using GW0742, restores in large part the age-related loss of myonuclei.

\section{Materials and methods}

\section{Animals}

Animals were maintained in a 12/12 h lighting cycle and received food (UAR, France) and water ad libitum. All experimental procedures were conducted according to French legislation. Ten-week-old male C57BL6J (Janvier, France) and 10 weeks and 19 month-old male B6D2 (maintained in our animal facility) were used in the various experiments. We always used four animals per condition to obtain statistical values. Animals were killed after the indicated times by cervical dislocation, and tibialis anterior muscles were harvested immediately after killing.

Animals over-expressing PPAR $\beta$ specifically in skeletal muscle were generated as previously described [18]. Briefly, B6D2 mice harbouring a loxP-stop-loxP-PPAR $\beta$-hygromycine construction were crossed with $\mathrm{B} 6 \mathrm{D} 2$ mice expressing Cre recombinase under human skeletal actin (HSA) promoter [20]. All animals were maintained hemizygous for their transgene. Presence of the transgenes was verified by polymerase chain reaction (PCR) analyses of tail DNA (REDExtract-N-Amp Tissue PCR Kit, Sigma). Animals harbouring the two transgenes were used as PPAR $\beta$ overexpressing mice, while animals harbouring the HSACre transgene only were used as control.

\section{Injections}

GW0742, a PPAR $\beta$-specific activator [38], was dissolved in Dulbecco's modified Eagle's medium/dimethyl sulphoxide (DMSO) 6\% (Gibco) and injected subcutaneously once a day $(9$ A.M.) at $1 \mathrm{mg} / \mathrm{kg}$. Control animals received vehicle at 9 A.M.. 
Cyclosporine A (Sigma) treatments were performed twice a day ( 9 A.M. and 6 P.M.) by subcutaneous injections at $25 \mathrm{mg} / \mathrm{kg}$ in DMSO. In these experiments, GW0742 was injected subcutaneously once a day (2 P.M.) at $1 \mathrm{mg} / \mathrm{kg}$. Injections of vehicle were performed at 9 A.M., 2 P.M. and 6 P.M. (Control group), 9 A.M. and 6 P.M. (GW group) and 2 P.M. (CsA group).

BrdU (Sigma) treatments were performed once a day (9 A. M.) by intra-peritoneal injections of the compound at $100 \mathrm{mg} /$ $\mathrm{kg}$ in $0.9 \% \mathrm{NaCl}$. In these experiments, GW0742 was injected subcutaneously once a day (2 P.M.) at $1 \mathrm{mg} / \mathrm{kg}$. Injections of vehicle were performed at 9 A.M. and 2 P.M. in control groups.

\section{Immunofluorescence analysis}

Tibialis anterior (TLA) muscles and duodenum were harvested and frozen in tissue embedding medium (VWR International) immediately after mice were killed. Tenmicrometre cryosections were performed from the middle part of muscle or from duodenum, placed on poly-lysine coated slides (VWR International) and processed for immunofluorescence analyses. Mouse monoclonal NFATc1 (7A6, sc-7294, Santa Cruz Biotechnology) and goat antimouse fluorescein conjugate antibodies were both used at 1:200 dilution. For BrdU immunofluorescence, cryosections were fixed on slide according manufacturer's protocol and then incubated 45 min with an anti-BrdU antibody (Anti-Bromodeoxyuridine-Fluorescein, Roche). Finally, slides were mounted with Vectashield containing DAPI (H-1200, Vector laboratories, Burlingame, CA, USA). Slides were viewed under an epifluorescence microscope connected to a digital camera with the Spot software (Universal Imaging).

Histological and immunohistochemical analysis

TLA muscles and duodenum were harvested, fixed in $4 \%$ paraformaldehyde (PFA) overnight, dehydrated and then embedded in paraffin. Paraffin sections $(5 \mu \mathrm{m})$ were used for either BrdU or PCNA antigen detection using M.O.M. Kit (PK-2200, Vector Laboratories). BrdU (11170376001, Roche), PCNA (PC10, Sc-56, Santa Cruz Biotechnology) and mouse monoclonal antibodies were used in a 1:50 and 1:100 dilution, respectively. DAB (SK-4100, Vector Laboratories) served as a substrate. Nuclei were counterstained with haematoxylin. Slides were viewed under an epifluorescence microscope connected to a digital camera with the Spot software (Universal Imaging).

Single-fibre isolation

Single fibres were isolated. Both fibre length and myonuclear number were assessed as described by Brack et al. [4].
Briefly, TLA muscles were fixed in 4\% PFA during 2 days at room temperature. Muscles were then treated $2 \mathrm{~h}$ in $40 \%$ $\mathrm{NaOH}(w / v)$ and agitated vigorously for $10 \mathrm{~min}$. Released fibres were washed in phosphate-buffered saline (PBS; pH 7.4) and stored at $4{ }^{\circ} \mathrm{C}$ in PBS $0.05 \%$ azide.

Myonuclear density analysis

After DAPI staining, images of 40 single isolated fibres per animal (four animals per group) were captured using a Zstacking procedure on a Zeiss Apotome ( $\times 10$ objective), then Z-projected using the open source ImageJ software (Wayne Rasband, National institutes for Health). Fibre diameters were measured at six locations over at least $500 \mu \mathrm{m}$ length of the fibre, and all nuclei were counted using Olympus DP-Soft software. Values obtained were averaged to obtain mean value per fibre. Any damaged areas of the fibres were not analysed.

Sodium dodecyl sulfate polyacrylamide gel electrophoresis and Western blot

Total TLA lysates from the mice treated with GW0742 or vehicle alone (DMSO) were prepared, electrophoresed and blotted on polyvinylidene difluoride membrane. Subcellular fractionation of TLA muscles was performed using the Qproteome $^{\mathrm{TM}}$ Cell Compartment Kit (Quiagen) according to manufacturer's instructions. The following antibodies were used at the indicated dilutions for immunodetection: Pan A calcineurin (AB1695, Chemicon International) 1:1,000, polyclonal anti P85 (PI3K subunit) from rabbit (06-496, Upstate, Lake Placid, NY, USA) 1:1,000, polyclonal anti CREB from rabbit (kind gift of Dr. M. Montminy, San Diego, USA) 1:2,000, polyclonal anti Rho GDIa from rabbit (A-20, sc-360, Santa Cruz Biotechnology) 1:500, polyclonal anti acetyl-histone 3 from rabbit (06-599, Upstate, Lake Placid, NY,USA) 1:1,000, monoclonal NFATc1 from mouse (7A6, sc-7294, Santa Cruz Biotechnology) 1:200, monoclonal NFATc3 from mouse (F-1, sc8405, Santa Cruz Biotechnology) 1:200, peroxidase-coupled anti-rabbit and peroxidase-coupled anti-mouse secondary antibodies (Vector Laboratories) 1:5,000.

Quantitative reverse transcription PCR

Reverse transcription was performed using $0.2 \mu \mathrm{g}$ of total RNA from muscle of 10 week-old and 19 month-old C57B16 mice (five animals per group), a Core kit (RTRTCK-03, Eurogentec) according to manufacturer's instruction and a mix of random primers $(9$ mers $)$ and oligodT. qPCR was performed on SDS7900HT (Applied Biosystem) using Mesagreen qPCR kit for SYBR (Eurogentec) and the following primers: 
PPAR $\beta$ : 5'-AGATGGTGGCAGAGCTATGACC-3'; 5'-TCCTCCTGTGGCTGTTCC-3'.

Catalase: 5'-GGATCCTGACATGGTCTGGG-3'; 5'TGGAGAGACTCGGGACGAAG-3'.

PDK4: 5'-GCATTTCTACTCGGATGCTCAATG-3'; 5'-CCAATGTGGCTTGGGTTTCC-3'.

36B4: 5'-TCCAGGCTTTGGGCATCA-3'; 5'CTTTATCAGCTGCACATCACTCAGA-3'.

Data were all normalised using 36B4 as housekeeping gene.

Statistical analysis

The effect of the duration of treatment was performed by a one-way analysis of variance (ANOVA) test. Twoway ANOVA tests were performed for comparisons between groups (age and treatment; age and transgenicity). When significant changes were observed in ANOVA tests, Fisher's protected least significant difference post hoc test was applied to locate the source of significant differences. When two groups were compared, we used a Student's $t$ test. Analyses were performed with Stat'View Abacus Concept version 5. Hierarchical ascendant classifications were performed for the determination of fibre groups according to nuclei $/ \mathrm{mm}$ of fibre length. Results are presented as means $\pm \mathrm{SD}$ with significance accepted when $p<0.05$.

\section{Results}

PPAR $\beta$ pathway activation promotes an increase in myonuclear density in TLA muscle

The effects of PPAR $\beta$ over-expression on myonuclear density were first investigated by quantification of myonuclear number per millimetre of fibre length in diamidino-2phenyl-indole (DAPI)-stained isolated fibres, prepared from TLA muscle of adult B6D2 PPAR $\beta$ transgenic mice and control littermates (Tg and Ct; Fig. 1a). These experiments revealed that muscle-specific PPAR $\beta$ over-expression leads to a $14 \%$ increase of nuclei number per millimetre of fibre length $(92 \pm 1.32, n=160$ fibres for controls versus $105 \pm 3.2$, $n=160$ fibres for PPAR $\beta$ transgenic mice, $p=0.003$ ). Using ascendant hierarchical classification, we defined three groups of myofibres, i.e. those containing less than 85 nuclei/mm $(F<85)$, those containing a number of nuclei comprised between 85 and 100 nuclei/mm $(85<F<100)$ and those containing more than 100 nuclei/mm $(F>100)$. As shown in Fig. 1b, PPAR $\beta$ over-expression induced major changes in myofibre distribution in these three groups with reduction of myofibre numbers in both the
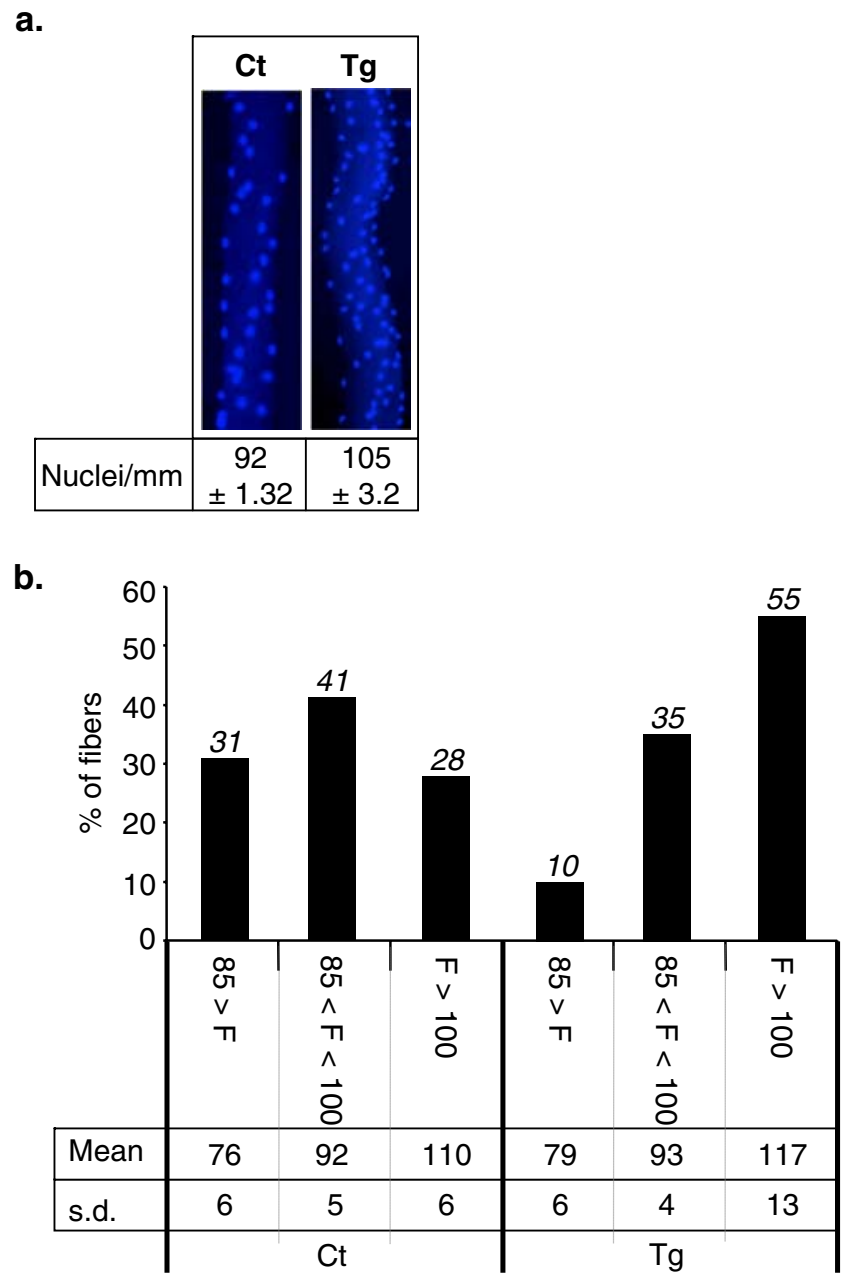

Fig. 1 Muscle-specific PPAR $\beta$ over-expression promotes an increase of myonuclear density. a Representative isolated DAPI-stained fibres harvested from tibialis anterior of 10-week-old control $(C t)$ and PPAR $\beta$ transgenic $(T g)$ B6D2 mice. Global myonuclear density is indicated as myonuclei number per millimetre of fibre length $(n=160$, four animals per group, 40 fibres per animal). b Distribution of myofibres population in TLA from control and PPAR $\beta$ overexpressing mice. Myonuclei in isolated DAPI-stained fibres $(n=160$, four animals per group, 40 fibres per animal) harvested from tibialis anterior of 10 -week-old control $(C t)$ and PPAR $\beta$ transgenic $(T g)$ B6D2F1 mice were quantified and pooled using ascendant hierarchical classification in three groups of fibres containing (1) less than 85 nuclei, (2) from 85 to 100 nuclei and (3) more than 100 nuclei/mm of fibre length. Percentage of each group, mean number of nuclei in each group (Mean) and standard deviation (s.d.) are reported for control $(C t)$ and PPAR $\beta$ transgenic $(T g)$ mice

$F<85(31 \%$ to $10 \%)$ and $85<F<100 \quad(41 \%$ to $35 \%)$ groups, while the number of fibres in the $F>100$ group is notably increased ( $28 \%$ to $55 \%)$.

We then investigated the effects of pharmacological PPAR $\beta$ activation on myonuclear density by treating 10-week-old C57B16 male mice with GW0742, a PPAR $\beta$ specific agonist [38]. The number of myonuclei/mm fibre length was determined at increasing times after GW0742 
or vehicle injections. We first noticed a significant strain difference concerning the myonuclear density ( $92 \pm 1.32$ and $86 \pm 1.40$, in B6D2 and C57B16 mice, respectively) as well as the distribution in the three predefined groups between B6D2 and C57B16 mice (compare Ct in Fig. 1b to Fig. 2b). As expected, vehicle treatment did not affect myonuclear density nor distribution in the three predefined groups of fibres (not shown). On the contrary, PPAR $\beta$ activation promoted a fast increase in myonuclear density with an $11 \%(p<0.0001)$ increase after 1 day and a maximal augmentation of $20 \%(p<0.0001)$ reached after 2 days of treatment (Fig. 2a). Classification of fibres in the three predefined groups revealed that, as previously observed in PPAR $\beta$ transgenic mice, pharmacological PPAR $\beta$ activation resulted in time-dependent and notable changes in fibre group distribution in favour of fibres with a high myonuclear density. This shift towards the $F>100$ group is progressive
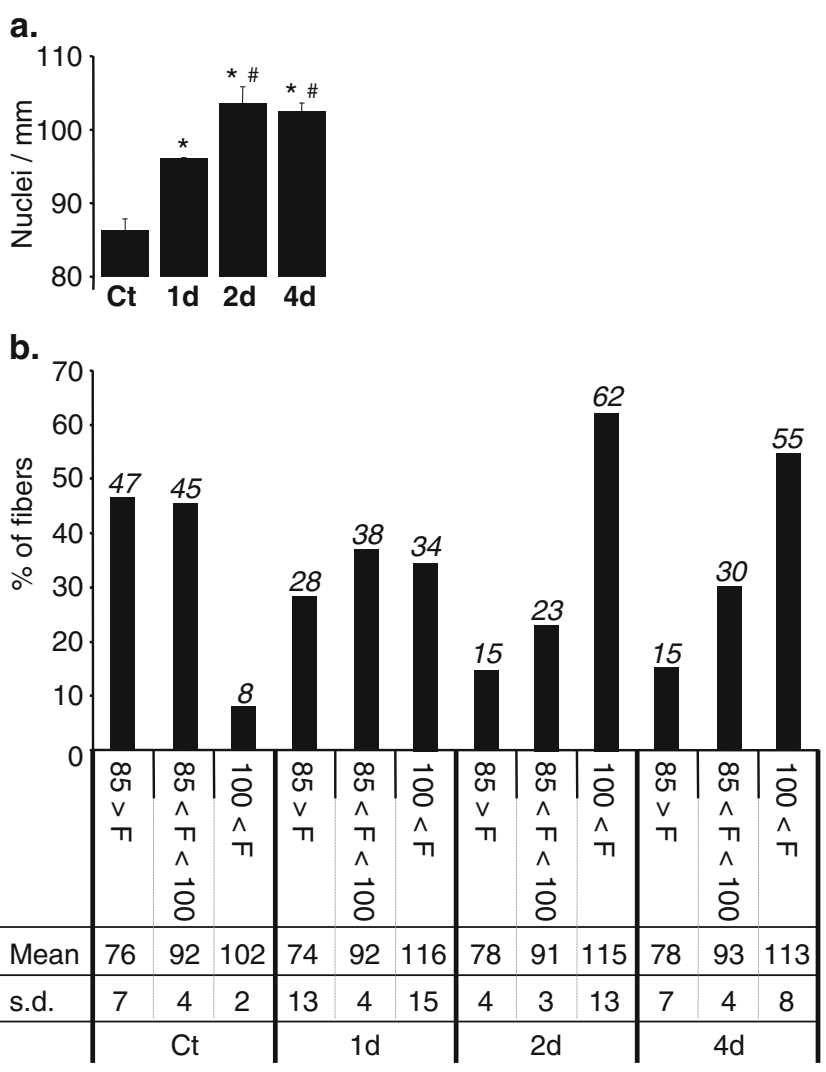

Fig. 2 PPAR $\beta$ pharmacological activation induces an increase of myonuclear density. a Quantification of myonuclei number in isolated DAPI-stained fibres ( $n=160$, four animals per group, 40 fibres per animal) harvested from tibialis anterior of 10-week-old C57B16 mice for different times of treatment with vehicle $(C t)$ or PPAR $\beta$ agonist GW0742 (1 day (1d), 2 days $(2 d)$ and 4 days $(4 d)$ ). ${ }^{*} p<0.001$, different from vehicle-treated group $(C t)$; pound sign $p<0.01$, different from 1 day treated animal group (1d). b Distribution of myofibres population counted in a using the same classification as in Fig. $1 b$. Percentage of each group, mean number of nuclei in each group (Mean) and standard deviation (s.d.) are reported for each period of treatment with GW0742 from $8 \%$ to $34 \%$ after 1 day and to a maximum of $62 \%$ reached after 2 days, with a parallel decrease of percentage of fibres in both $F<85$ group ( $47 \%$ to $28 \%$ after 1 day and to $15 \%$ after 2 days) and $85<F<100$ group ( $45 \%$ to $38 \%$ after 1 day and to $23 \%$ after 2 days; Fig. $2 b$ ).

Pharmacological PPAR $\beta$ activation does not promote cell division in TLA muscle

The fast and important increase in myonuclear density as well as hyperplasia suggests major events of MPC activation and fusion to myofibres. However, the quickness of myonuclear accretion in response to PPAR $\beta$ activation argues against a process requiring cell proliferation. To investigate directly the effect of PPAR $\beta$ activation on cell proliferation in TLA muscle, we explored by immunochemistry the expression of a well-known mitosis marker, the proliferating cell nuclear antigen (PCNA), in muscles from animals receiving or not GW0742 for various times. Sections of the duodenum from control animals were used as positive control and displayed, as expected, an important labelling in the crypts (Fig. 3a). In contrast, nearly no PCNA-positive myonuclei were detectable in sections from control animals (Fig. 3b). As shown in Fig. 3, PPAR $\beta$ activation did not increase the number of PCNA-positive myonuclei, whatever the period of treatment with GW0742 was, i.e. 5 h (Fig. 3c), 24 h (Fig. 3d), or 48 h (Fig. 3e, f). However, after $48 \mathrm{~h}$ of PPAR $\beta$ agonist treatment, several fibres with centrally located myonuclei can be observed as a mark of myonuclear accretion (Fig. 3e and f). These results suggest that PPAR $\beta$-promoted myonuclear accretion did not involve proliferation of MPCs. Finally, we did detect some PCNA-positive cells but almost only in blood vessels (Fig. $3 \mathrm{~d}, \mathrm{~h}-\mathrm{j}$ at high magnification).

To confirm these observations, bromodeoxyuridine (BrdU) incorporation into DNA was used. In vivo BrdU labelling technique allows identification of MPCs that have proliferated, migrated and either incorporated into existing myofibres or having been implicated in the formation of new fibres [16, 35]. BrdU incorporation into DNA was determined by two different methods, indirect immunofluorescence on cryosections and immunochemistry on paraffin-embedded sections. As shown in Fig. 4a, b, sections from the duodenum of control animals that received for 1 (Fig. 4b) or 2 days (Fig. 4a) daily injections of BrdU validated the method to follow cell proliferation in vivo, as BrdU-positive cells are detected both in crypts, where the cells are proliferating, and in the lower parts of the villi that contain epithelial cells, which have proliferated in the crypts (Fig. 4b) and then migrated during their differentiation towards the villous apex (Fig. 4a). Data 
Fig. 3 GW0742-promoted myonuclear remodelling is independent of cell proliferation in tibialis anterior. Immunohistochemical localization of PCNA, a well-known mitotic marker, in a section of duodenum as positive control, $\mathbf{b}, \mathbf{g}$ section of TLA muscles from vehicle-treated animals, $\mathbf{c}-\mathbf{j}$ sections of TLA muscles from animals receiving GW0742 for various times: c, h 5 h, d, i 24 h, e, f, j 48 h. Note the important labelling in the crypts and the quasi absence of positive myonuclei in both control and GW0742-treated animals. PCNA signals were often detected in blood vessels (arrows in $\mathbf{d}, \mathbf{h}-\mathbf{j}$ ) but rarely in myonuclei (arrows in c). Finally, note the elevated number of centrally located nuclei (arrowhead in $\mathbf{e}, \mathbf{f}$ ). Scale bars, $50 \mu \mathrm{m}$
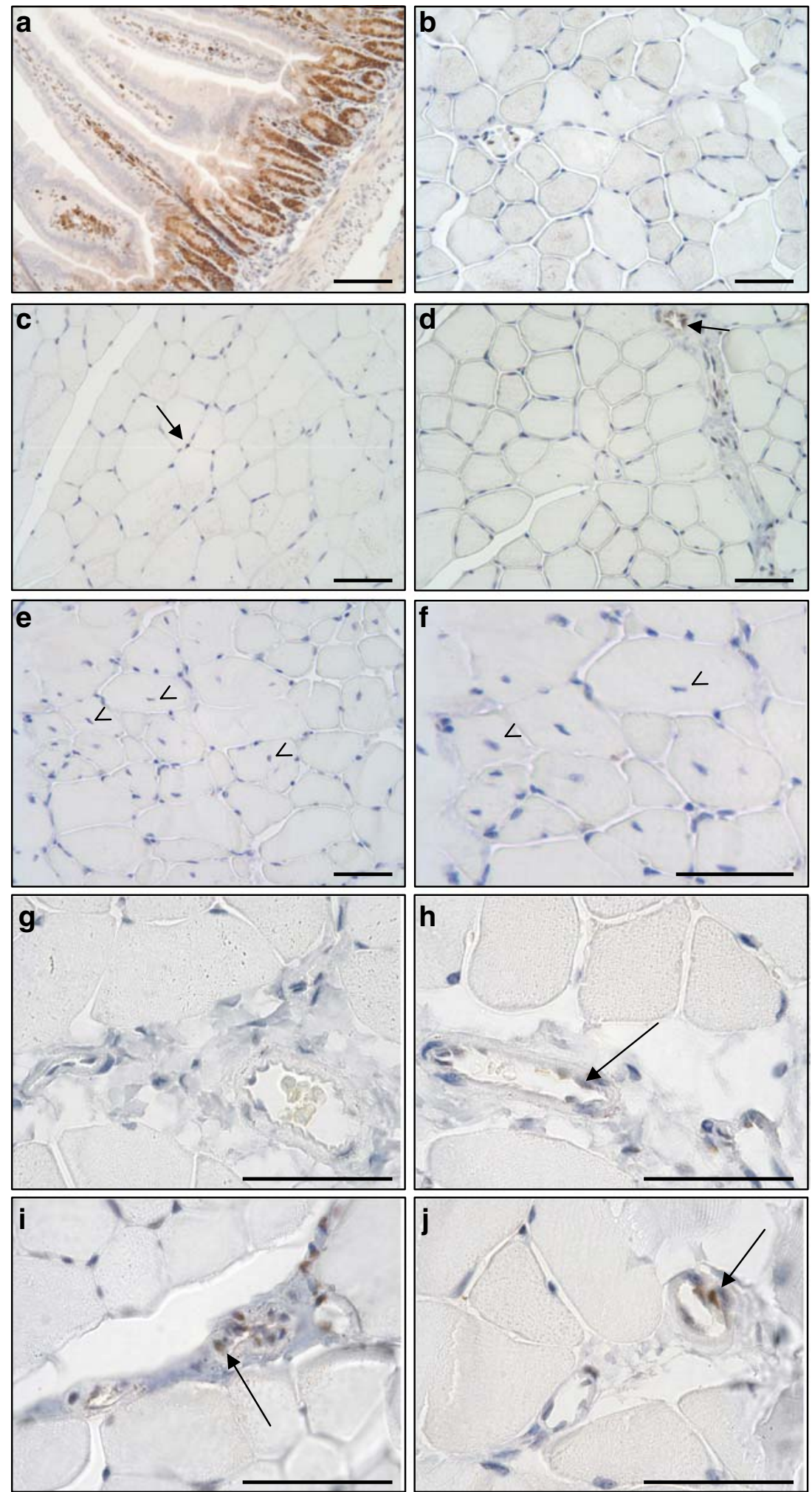

presented in Fig. 4 confirmed that PPAR $\beta$-promoted muscle remodelling does not implicate cell proliferation as the number of BrdU-positive nuclei remained very low in muscle from animals treated for 2 days with GW0742. Less than $1 \%$ of nuclei were BrdU-positive, and no significant difference was found compared to muscles from untreated animals. Furthermore, as previously observed, several myofibres containing central nuclei can be evidenced in muscles from animals treated for $48 \mathrm{~h}$ with GW0742 (Fig. 4c, e, f). Interestingly, these nuclei remained BrdU- 

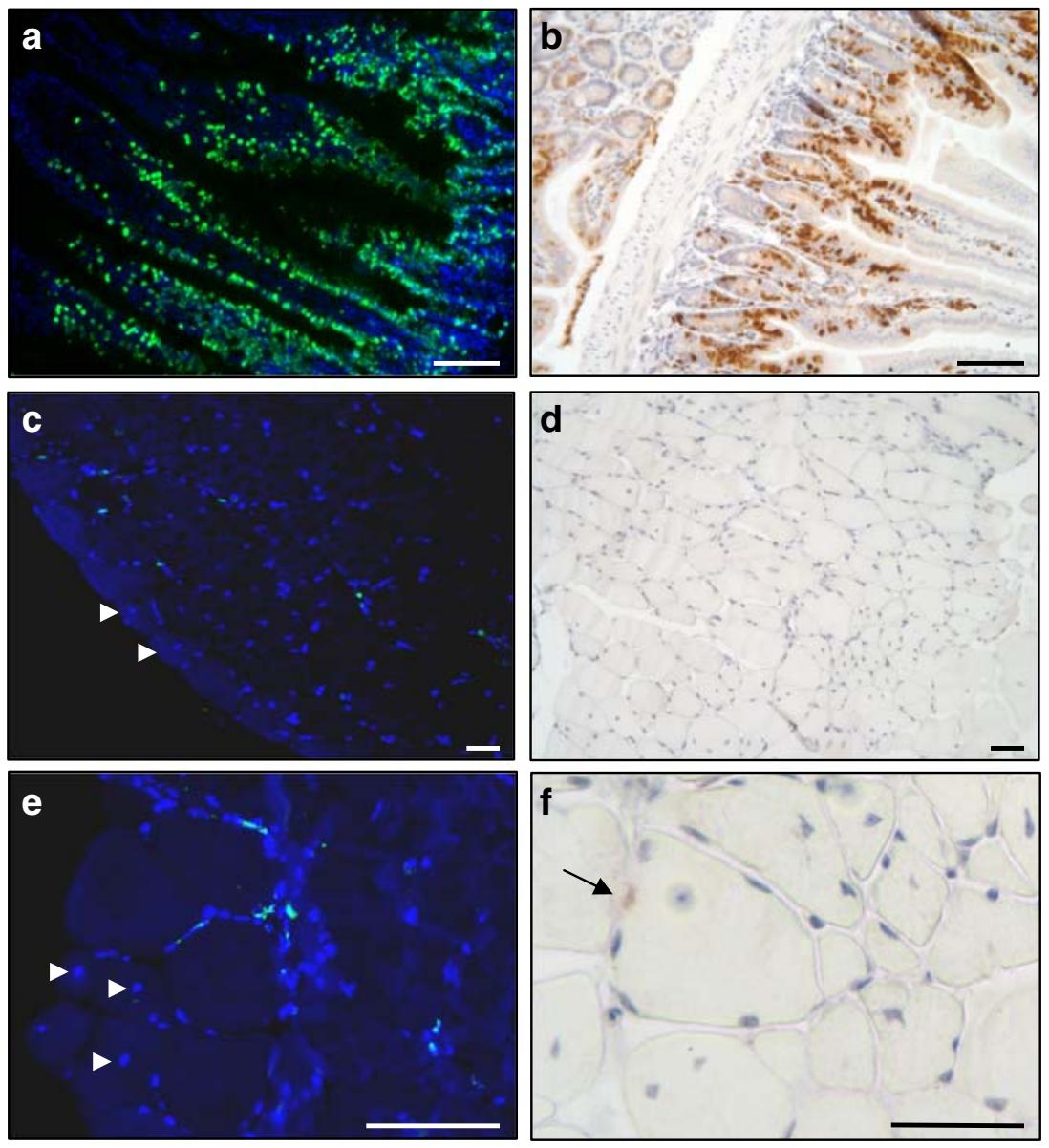

Fig. 4 GW0742-promoted myonuclear remodelling does not require cell division in tibialis anterior. Mice were injected with BrdU and or not with GW0742. Duodenum $(\mathbf{a}, \mathbf{b})$ or TLA muscle $(\mathbf{c}-\mathbf{f})$ harvested from $24 \mathrm{~h} \mathrm{(b)}$ or $48 \mathrm{~h} \mathrm{(a,} \mathrm{c-f)} \mathrm{post} \mathrm{GW0742} \mathrm{treatment,} \mathrm{were} \mathrm{either}$ frozen in tissue-embedding medium or fixed, dehydrated and embedded in paraffin. Frozen sections on slides were stained with anti-BrdU antibody coupled to fluorescein (a, c, e) and mounted using Vectashield containing DAPI as described in "Materials and methods". Positive cells are detected in blood vessels, and very few myonuclei

are labelled (c, e). Arrowheads indicate myofibres with central nucleus (c, e). Paraffin sections were stained with anti-BrdU antibody (b, d, f) as described in "Materials and methods", and nuclei were counterstained with haematoxylin. Very few myonuclei are labelled (d, and arrow in $\mathbf{f}$ ); on the contrary, a large number of myofibres with one or more central nuclei are visible $(\mathbf{d}, \mathbf{e}, \mathbf{f})$. Note the increased $\mathrm{BrdU}$ labelling in the duodenum sections between $24 \mathrm{~h}$ (b) and $48 \mathrm{~h}$ (a) of the BrdU pulse. Scale bar, $50 \mu \mathrm{m}$

negative. As central nuclei are marks of the fusion of MPCs to fibres and/or newly formed myofibres, these observations also strongly support the conclusion that myonuclear accretion and fibre hyperplasia promoted by PPAR $\beta$ activation took place without MPC proliferation.

Positive effects of PPAR $\beta$ activation on myonuclear density are dependent of the calcineurin/NFAT pathway

We previously provided evidences that the active calcineurin pathway is required for the myogenic and angiogenic responses to PPAR $\beta$ activation in the adult mouse [10]. To test whether an active calcineurin pathway was required for the PPAR $\beta$-promoted myonuclear accretion, we explored the effects of co-administration of cyclosporine A (CsA), a potent inhibitor of calcineurin/nuclear factor of activated T-cells (NFAT) pathway, on TLA myonuclear density in mice treated by GW0742 for 2 days.

As shown in Fig. 5a, b, CsA administration alone neither affected the myonuclear density nor the distribution in the three defined fibre groups. On the contrary, CsA administration totally blunted the PPAR $\beta$-dependant increment of global myonuclear density (from 86 to 104 nuclei/mm in the absence and to 87 nuclei $/ \mathrm{mm}$ in presence of CsA; Fig. 5a). Calcineurin inhibition strongly reduced the redistribution of myofibres towards the group with the highest myonuclear density (shift from $8 \%$ to $62 \%$ in the absence of CsA versus shift from $8 \%$ to $20 \%$ when CsA was co-administrated; Fig. 5b).

Our data also indicated that in TLA muscle, GW0742 treatment did not promote an increase of calcineurin at the protein level (Fig. 6a) but rather provokes an induction of 


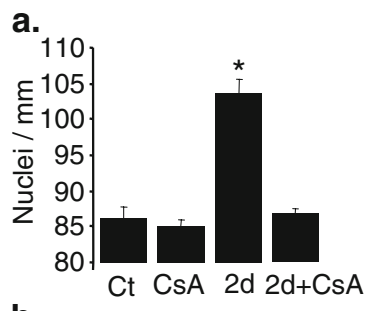

b.

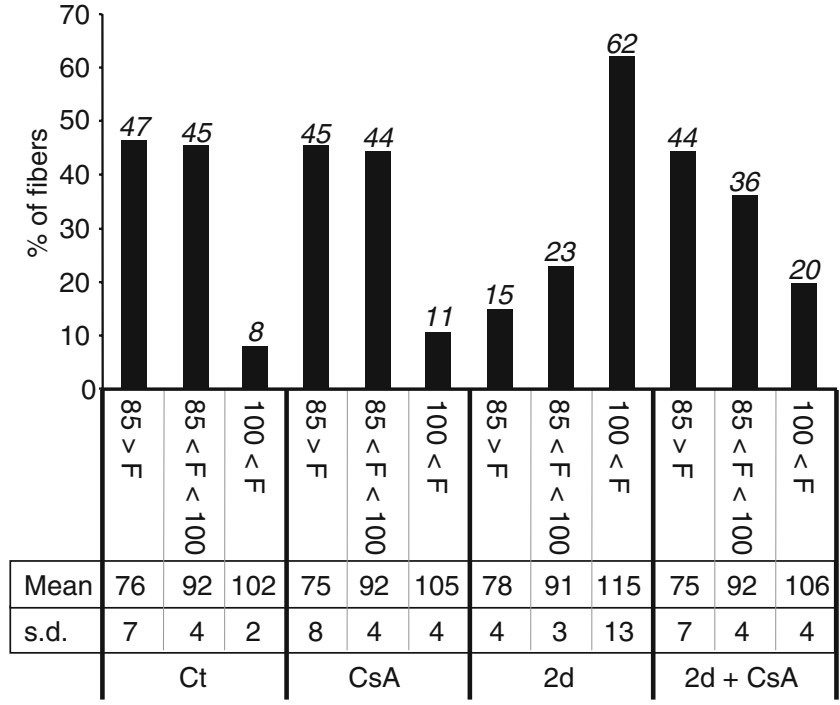

Fig. 5 Positive effects of PPAR $\beta$ on myonuclear density are calcineurin dependent. a Quantification of nuclei number in isolated DAPI-stained fibres harvested from tibialis anterior of 10 -week-old C57B16 animals $(n=160$, four animals per group, 40 fibres per animal), treated 2 days with vehicle $(C t)$, cyclosporine A (CsA), PPAR $\beta$ agonist GW0742 $(2 d)$ or PPAR $\beta$ agonist GW0742 and cyclosporine A $(2 d+C s A) .{ }^{*} p<0.01$, different from $\mathrm{Ct}$, CsA and $2 \mathrm{~d}+\mathrm{Cs}$ A groups. b Distribution of myofibres population counted in a using the same classification as in Fig. 1b. Percentage of each group, mean number of nuclei in each group (Mean) and standard deviation (s.d.) are reported for each treatment

its phosphatase activity as attested by the rapid nuclear translocation of nuclear factor of activated $\mathrm{T}$ cells $\mathrm{C} 1$ and C3. Indeed, enhanced NFATc1 nuclearization can be evidenced as soon as $5 \mathrm{~h}$ after GW0742 treatment (Fig. 6b, c). It remained high at $24 \mathrm{~h}$ of treatment and returned to control value after $48 \mathrm{~h}$ (Fig. 6c). NFATc3 nuclearization can be evidenced after $24 \mathrm{~h}$ of PPAR $\beta$ agonist treatment, and it returned to control values after $48 \mathrm{~h}$ of treatment.

Ageing promotes a decrease in myonuclear density, while PPAR $\beta$ agonist treatment restores a juvenile phenotype

Myonuclear density is negatively regulated by ageing [4, 5]. In order to explore a possible role of PPAR $\beta$ in this a process, we first investigated the effect of ageing on PPAR $\beta$ expression by comparing the amounts of the corresponding mRNA in mouse TLA from adult (10-weekold) and aged (19-month-old) mice. As shown in Fig. 7, PPAR $\beta$ mRNA was down-regulated by more than $30 \%$ ( $p=$ $0.03, n=5)$ in aged mouse muscles when compared to young mouse muscles. To check whether the decreased expression of PPAR $\beta$ impacts on gene regulation, we also quantified mRNA for two PPAR $\beta$-target genes, namely catalase, that plays a crucial role in the protection against oxidative stress [23], and pyruvate dehydrogenase kinase 4 (PDK4) that is involved in metabolic regulations [7]. These experiments revealed that in aged mice, both genes were down-regulated $(40 \%, p=0.01$, and $75 \%, p=0.001$ for catalase and PDK4, respectively; Fig. 7a). However, $\operatorname{PPAR} \beta$ pathway remains active in aged mice as 4 days of GW0742 treatment promoted an up-regulation of these target genes (1.76-fold, $p=0.034$, and 6.19-fold, $p=0.047$ for catalase and PDK4, respectively; Fig. 7b). As expected, GW0742 treatment did not modify PPAR $\beta$ expression.

The effect of ageing on myonuclear density was next investigated in TLA muscles from young and aged B6D2 control mice ( $\mathrm{Ct}$ and $19 \mathrm{Ct}$ in Fig. 8a, b). As shown in Fig. 8a and in agreement with other reports [5], global myonuclear density was slightly but significantly lower in aged mice when compared to young adult animals $(-5 \%$, $p=0.0057)$. The effect of ageing on myonuclear density is further evidenced when evaluating the fibre distribution profile in the previously defined groups. In aged mice, the number of fibres in the $F<85$ group was increased by 1.35 fold $(31 \%$ to $42 \%)$, whereas the fibre numbers in $F>100$ and $85<F<100$ groups were reduced 1.22- and 1.17-fold, respectively compared to those of young mice (Fig. $8 b$ ). Furthermore, the mean value in the $F<85$ group seems to be lower in aged animals than in young adult animals, whereas other mean values remain stable (Fig. 8b).

To explore a possible beneficial action of PPAR $\beta$ pathway activation on myonuclear density, we next investigated the effects of muscle specific PPAR $\beta$ overexpression on the ageing-related loss of myonuclei. In elderly PPAR $\beta$ transgenic animals, we have observed a significant reduction in global myonuclear density $(-7 \%$, $p<0.0052)$ and a shift towards fibres that contain fewer nuclei (Tg and 19Tg in Fig. 8a, b) when compared to their younger counterparts. Despite this reduction, global myonuclear density in aged transgenic mice remained in the same order of value than that found in young untreated mice (compare CT and 19Tg in Fig. 8a). Furthermore, the percentage of fibres in the $F>100$ group remained significantly higher in old transgenic animals than in control young animals $(F>100=28 \%$ and $46 \%$ in CT and 19Tg, respectively. Fig. 8b). Finally, we studied the effects of pharmacological PPAR $\beta$ activation on myonuclear density in young and old B6D2F1 mice (GW and 19GW in Fig. $8 \mathrm{a}, \mathrm{b}$ ). In young control mice, 4 days treatment with 
Fig. 6 GW0742 induces calcineurin A-dependent NFAT nuclearization. a Calcineurin and P85 Western blot analysis after control treatment (DMSO $5 H$ ) or different times of GW0742 treatment $(2,5,8$, and $24 \mathrm{~h})$. P85 is used as loading control. b Immunohistochemical localization of NFATc1 using cryosections of TLA muscles from mice treated $5 \mathrm{~h}$ with DMSO (DMSO 5H), GW0742 $(G W 5 H)$ or cyclosporine A and GW0742 (CsA $+G W 5 H)$. Note the increased NFATc1 nuclearization only in GW 5H-treated animals. c TLA muscles from mice treated 5 or $24 \mathrm{~h}$ with DMSO (DMSO 5h, DMSO 24h), or treated 5,24 , or $48 \mathrm{~h}$ with GW0742 ( $G W 5 h, G W 24 h, G W$ $48 h$ ) were used for subcellular fractionation in cytoplasmic $(C)$, nuclear $(N)$ and insolublechromatin-associated $(I)$ proteins and subsequent Western blot analysis. Note the increased nuclear localization of NFATc1 and NFATc3 in response to PPAR $\beta$ activation. CREB (nuclear), Rho GDI $\alpha$ (cytoplasmic) and acetylated histone $\mathrm{H} 3$ (H3, Chromatin associated) antibodies were used to evaluate the purity of each fraction. Scale bar, $50 \mu \mathrm{m}$
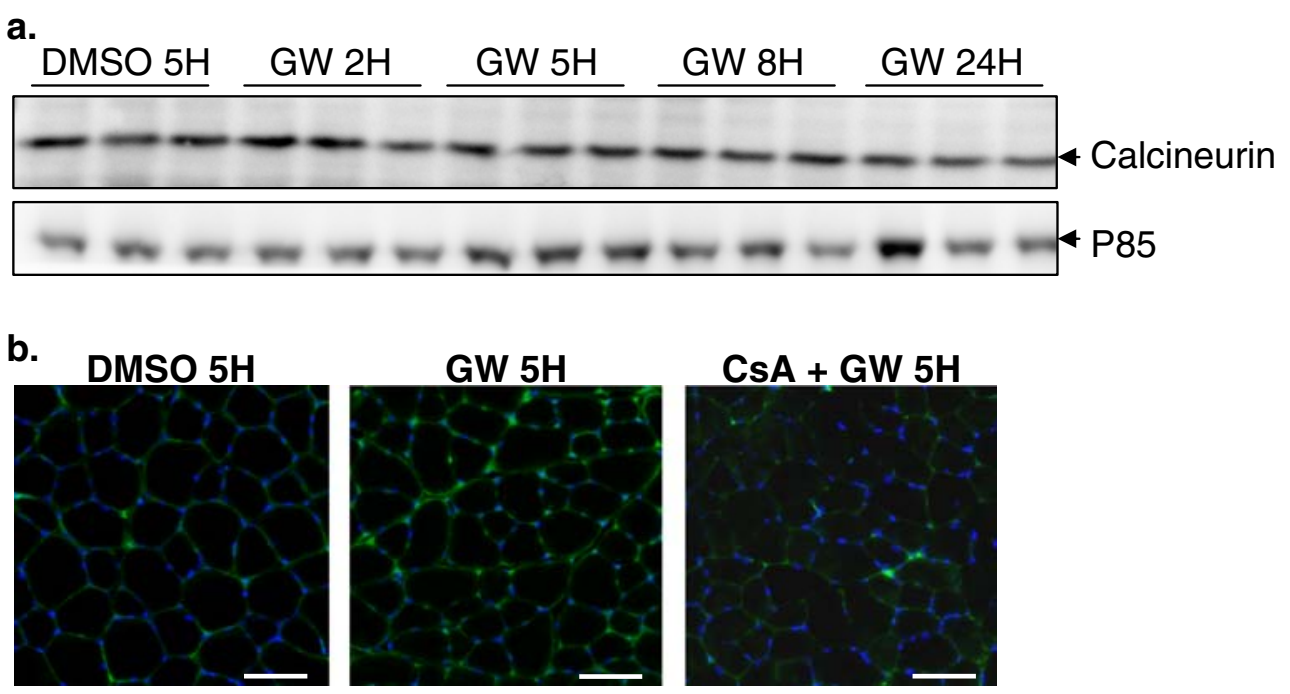

C.

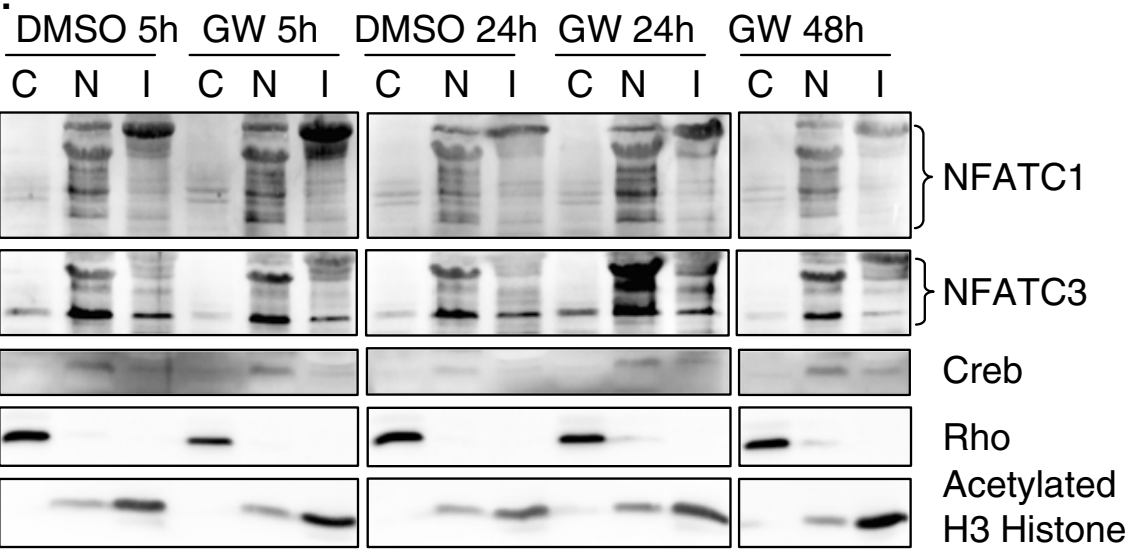

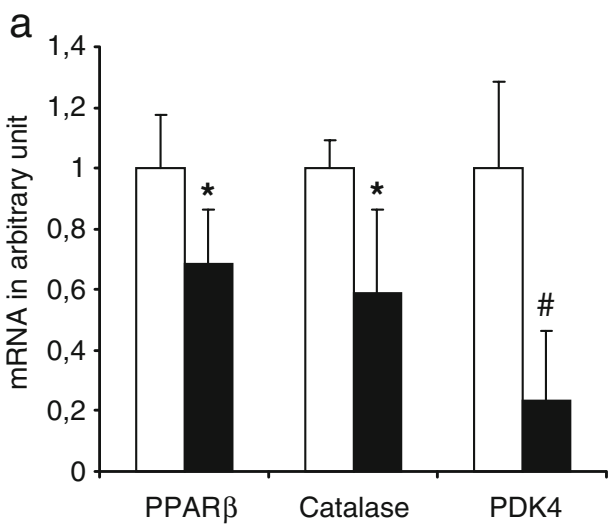

Fig. 7 Ageing reduces expression of PPAR $\beta$, catalase and PDK4 mRNAs. a Quantification of PPAR $\beta$, catalase and PDK4 using mRNAs from muscles of 10-week-old (white bar) and 19-month-old (dark bar) mice (five animals per group) and $\mathrm{qPCR}$ analyses as described in "Materials and methods". ${ }^{*} p<0.05$, different from 10 -week-old mice group; pound sign $p<0.005$, different from 10 -week-old mice group. b

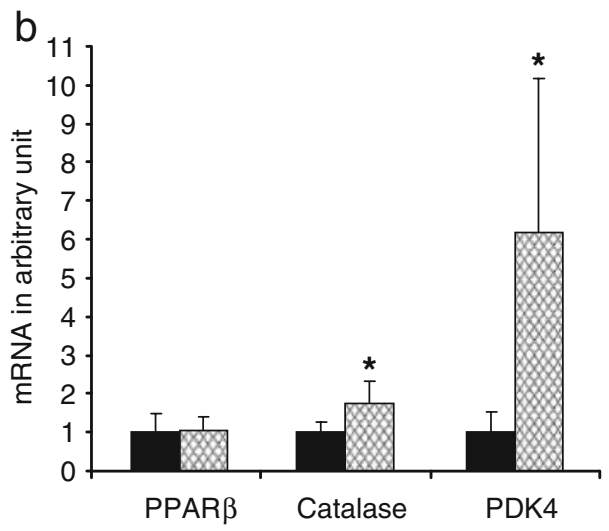

Quantification of PPAR $\beta$, catalase and PDK4 using mRNAs from muscles of 20-month-old mice treated (cross-hatched bar) or not (dark bar) during 4 days with GW0742 (four animals per group) and qPCR analyses as described in "Materials and methods". $* p<0.05$, different from 20-month-old untreated mice group. Results in $\mathbf{a}$ and $\mathbf{b}$ were normalised using 36B4 as housekeeping gene 
Fig. 8 Ageing promotes a 5\% decrease of myonuclear density, while PPAR $\beta$ agonist treatment restores a juvenile phenotype. a Quantification of nuclei number in isolated DAPI-stained fibres harvested from tibialis anterior of 10-week-old ( $\mathrm{Ct}, \mathrm{Tg}, \mathrm{GW})$ and 19-month-old $(19 \mathrm{Ct}, 19 \mathrm{Tg}$, $19 G W)$ B6D2 mice $(n=160$, four animals per group, 40 fibres per animal). Mice were either treated with vehicle only $(C t, 19 C t)$ or untreated PPAR $\beta$ transgenic mice $(\mathrm{Tg}, 19 \mathrm{Tg})$ or treated for 4 days with GW0742 $(G W, 19 G W) . * p<0.01$, different from 10-week-old mice groups $(C t, T g, G W)$; pound sign $p<0.05$, different from vehicletreated groups $(\mathrm{Ct}, 19 \mathrm{Ct})$. b Distribution of myofibres population counted in a using the same classification as in Fig. 1b. Percentage of each group, mean number of nuclei in each group (Mean) and standard deviation (s.d.) are reported for each experimental condition

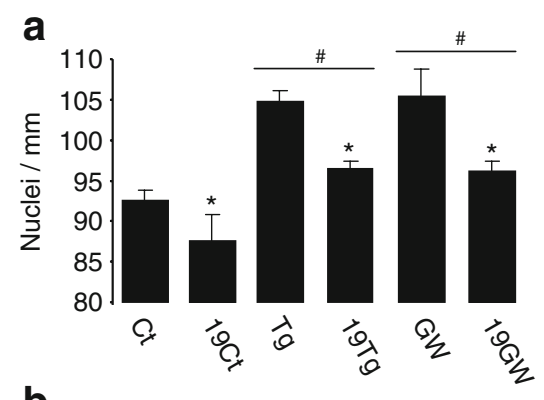

b

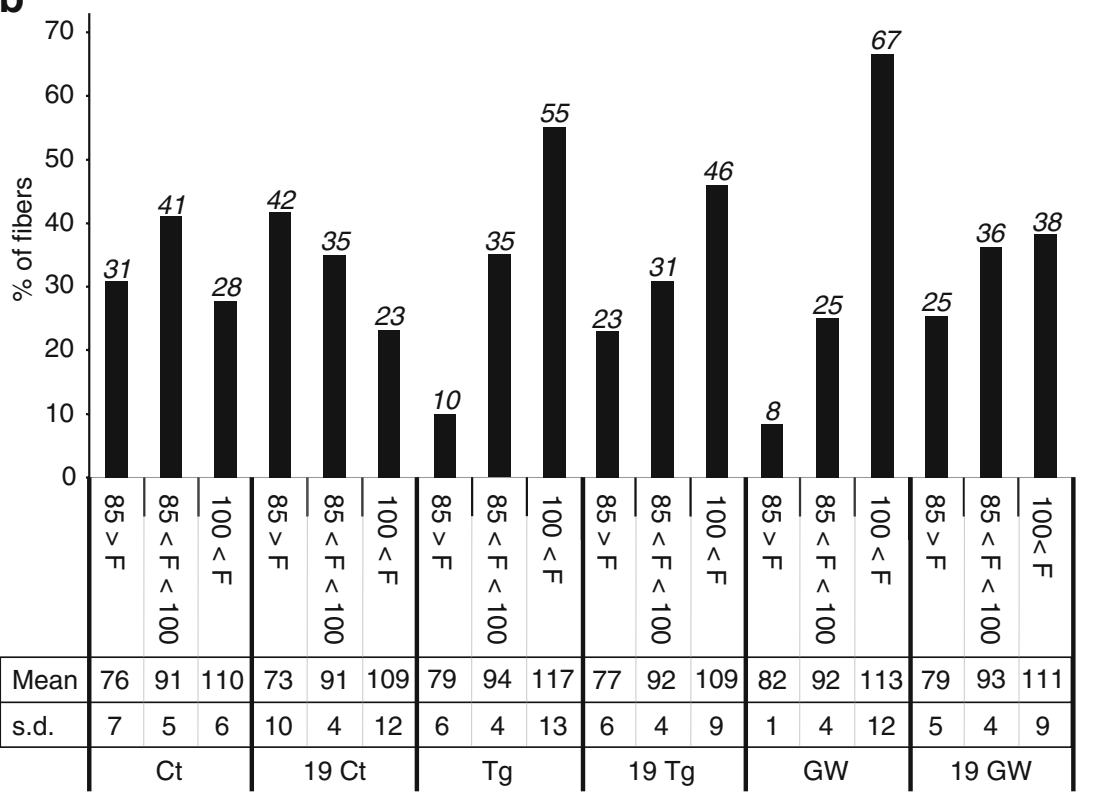

GW0742 resulted in an increase $(14 \%, p=0.048)$ in the global myonuclear density (Fig. 8a) and redistribution of fibres in favour of the $F>100$ group ( $28 \%$ to $67 \%$, Fig. 8 b). This augmentation is similar to that observed in PPAR $\beta$ over-expressing transgenic mice (compare CT, TG and GW in Fig. 8a) but is less important than the observed $20 \%$ increase in young C57Bl6-treated mice (Fig. 2a). Interestingly, in aged B6D2F1 mice (19GW), 4 days administration of PPAR $\beta$ agonist led not only to a $9 \%(p=0.0318)$ increase in the myonuclear density (compare $19 \mathrm{Ct}$ and $19 \mathrm{GW}$ in Fig. 8a) but also to a redistribution of fibres in the group which contained more than 100 nuclei/mm $(F>100 ; 23 \%$ to $38 \%$; Fig. 8 b). The percentage of fibres in the $F<85$ group was reduced ( $42 \%$ to $25 \%$ ), whereas the $85<F<100$ group remained stable (Fig. 8b). Interestingly, treatment allowed aged mice to reach similar global myonuclear density as 10week-old control mice (compare 19GW and Ct in Fig. 8a), almost the same fibre distribution profile (Fig. 8b) and slightly better mean values in the three groups, indicating that PPAR $\beta$ activation could compensate the age-related loss of myonuclei.
Ageing promotes a decrease in oxidative myofibre number, while PPAR $\beta$ agonist treatment restores a juvenile phenotype

To characterise the impact of ageing on fibre type composition and the effects of PPAR $\beta$ activation on this parameter, we used cross-sections around mid-portion of the TLA muscles from 10-week-old and 22-month-old animals treated or not for 4 days with GW0742 for in situ staining of succinate dehydrogenase activity, which is a marker of mitochondrial complex II content. In accordance with our previous observations [10], TLA from young adult C57B16 mice contains about $46 \%$ of SDH-positive fibres and $54 \%$ of SDH-negative fibres, and GW0742 treatment promotes an increment of the oxidative phenotype characterised by increased proportion of SDH-positive fibres (Table 1). TLA from aged animals displayed a less oxidative phenotype with decreased proportion of SDH-positive fibres (39.3\% in aged versus $46.3 \%$ in young animals). Interestingly, 4 days of GW0742 administration promoted an increase of SDH-positive fibre proportion in aged mouse 
Table 1 Ageing promotes a decrease of TLA oxidative fibre proportion, while PPAR $\beta$ agonist treatment restores a juvenile phenotype

\begin{tabular}{|c|c|c|c|c|c|c|}
\hline \multirow{2}{*}{$\begin{array}{l}\text { Age in month } \\
\text { C57B16 Mice }\end{array}$} & \multicolumn{3}{|c|}{2.5 months } & \multicolumn{3}{|l|}{22 months } \\
\hline & Control & GW96h & $p$ value & Control & GW96h & $p$ value \\
\hline SDH positive (\%) & $46.4 \pm 1.3$ & $54.6 \pm 1.9$ & $1.5 \mathrm{E}-05$ & $39.3 \pm 1.4$ & $47.6 \pm 2.4$ & 0.0067 \\
\hline SDH negative $(\%)$ & $53.6 \pm 1.3$ & $45.4 \pm 1.9$ & $1.5 \mathrm{E}-05$ & $60.7 \pm 1.4$ & $52.4 \pm 2.4$ & 0.0067 \\
\hline
\end{tabular}

In situ staining of succinate dehydrogenase activity using cross-sections around mid-portion of the TLA muscles from 10-week-old and 22-monthold animals treated or not for 4 days with GW0742

TLA, resulting in a phenotype that is nearly similar to that observed in young untreated animals (Table 1). This PPAR $\beta$-promoted increment of oxidative capabilities of TLA from aged animals was then confirmed by the determination of citrate synthase (CS) activity as a marker of the oxidative metabolism and lactate dehydrogenase (LDH) activity as a marker of glycolytic metabolism. These experiments showed that, after 4 days of PPAR $\beta$ agonist treatment, the CS specific activity was increased by $16.7 \%$ ( $p=0.002, n=4)$, while the LDH-specific activity remained unchanged $(p>0.5, n=4)$. Comparable effects were previously reported in PPAR $\beta$ transgenic animals [18].

\section{Discussion}

We previously reported that PPAR $\beta$ activation or overexpression in mice induces striking skeletal muscle oxidative and angiogenic remodelling $[10,18]$. We report here a new phenotype in both PPAR $\beta$ transgenic mice and PPAR $\beta$ agonist-treated mice, consisting in massive activation, recruitment and fusion of MPCs to both pre-existing and newly formed myofibres. Fusion of such a large number of myonuclei may represent a key event in the PPAR $\beta$-promoted oxidative muscle remodelling.

This newly described PPAR $\beta$-promoted phenotype is remarkable in magnitude and quickness. First, in B6D2F1 mice, muscle-specific PPAR $\beta$ over-expression or pharmacological activation induced a $14 \%$ increase in myonuclear density when compared to control animals. This myonuclear density increment is even more pronounced in GW0742-treated C57B16 mice which display a $20 \%$ augmentation. Taking into account that in the TLA of C57B16, PPAR $\beta$ agonist treatment also leads to a muscle hyperplasia corresponding to the generation of 600 new myofibres [10], it can be estimated that PPAR $\beta$ activation resulted in addition of about one million of new myonuclei to each muscle. Furthermore, these events of MPC activation, recruitment and fusion could also happen in other muscles, resulting in addition of several millions of new myonuclei per animal. The quickness of myonuclear accretion after PPAR $\beta$ administration is also very impressive. In both C57B16 and B6D2F1, GW0742 treatment promoted an increase in myonuclear density that was already detectable at day 1 and achieved at day 2 (Fig. 2). This process takes place in the same time frame that we have already determined for the PPAR $\beta$-promoted myogenic/angiogenic muscle remodelling [10]. Analysis of the fibre distribution depending on their myonuclear content per millimetre of fibre length $(F<85 ; 85<F<100 ; F>100)$ allowed a better description of the effects of PPAR $\beta$ pathway activation. Both PPAR $\beta$ over-expression and its pharmacological activation highly increased the number of fibres that contain more than 100 nuclei/mm fibre length (Fig. 1b and 2b). Furthermore, in GW0742-treated animals, we observed a time-dependent shift from the two classes of low myonuclear density fibres towards high myonuclear density fibres. Indeed, in C57B16, the fibres that contain less than 100 nuclei $(F<85$ and $85<F<100)$ represent $93 \%$ of the myofibres before the treatment, $66 \%$ after 1 day of treatment, and only $38 \%$ after 2 days of treatment (Fig. 2b). Since these fibres did not disappear, the most probable scenario is a rapid and progressive recruitment and fusion of MPCs to preexisting and newly formed fibres.

Another remarkable feature of the PPAR $\beta$-promoted myonuclear accretion is the finding that proliferation of MPCs is not required for such a remodelling (Figs. 3 and 4). This is in contrast with other pathological or physiological situations leading to muscle remodelling, such as adaptation to exercise, overload or muscle regeneration, in which a critical and obligatory step of MPCs proliferation has been established $[16,26]$. However, it should be noted that in these situations, muscle remodelling takes place within weeks and often follows muscle damage, whereas PPAR $\beta$-promoted muscle remodelling is achieved in 2 days without any histological sign of fibre deterioration. All our observations argue in favour of a model, in which the PPAR $\beta$ pathway activates a pool of MPCs that are "committed" to differentiate and able to fuse to fibres omitting the obligate step of proliferation. Existence of such cells has already been suggested by others [1, 11, 24, 43].

The central role of the calcineurin/NFAT pathway in the maintenance of fibre type composition and in muscle adaptation to physical exercise has been well documented 
(for review, see [3]). The calcineurin pathway has also been associated with MPC activation [8, 22, 34]. As cyclosporine A administration abolished both myogenic and angiogenic responses to PPAR $\beta$ activation, we previously proposed that active calcineurin pathway is required for PPAR $\beta$-promoted muscle remodelling [10]. Data presented here reinforce this model as demonstrating that treatment of mice with GW0742 did not affect calcineurin A expression but induced calcineurin A activation as shown by the rapid nuclearization of both NFATc1 and NFATc3 in TLA (Fig. 6). The finding that CsA administration impaired the PPAR $\beta$-dependent increase in global myonuclear density (Fig. 5a) as well as the redistribution of myofibres in the three defined fibre groups (Fig. 5b) strongly suggests that the calcineurin/NFAT pathway is involved directly in the PPAR $\beta$-promoted myonuclear accretion. Further work is required to fully characterise the signalling cascade that follows PPAR $\beta$-promoted NFAT activation.

A characteristic of ageing muscle is fibre atrophy and loss of myonuclei $[4,5]$. In particular, the regression in myonuclear content seems to be a key event in the process of age-related muscle atrophy. Our data confirmed that ageing leads to a reduction in global myonuclear density and to a poor fibre distribution profile (Fig. 8a, b). Furthermore, ageing results in a reduction of TLA muscle oxidative capabilities (Table 1), down-regulation of PPAR $\beta$ expression and transcriptional activity (Fig. 7). As we have demonstrated that PPAR $\beta$ pathway activation promotes both oxidative phenotype $[10,18]$ and myonuclear accretion (Figs. 1 and 2), it is tempting to speculate that PPAR $\beta$ down-regulation observed in muscle from aged animals is directly involved in the age-related reduction of both myonuclear density and oxidative phenotype in TLA. The findings showing that PPAR $\beta$ over-expression or pharmacological activation (Fig. 8a, b and Table 1) counteract, at least in part, the effects of ageing on these parameters suggest that PPAR $\beta$ activation could exert preventive or curative effects on both age-related muscle atrophy and reduction of oxidative phenotype.

The effect of such import of new genetic material on the functional and metabolic abilities of muscle cells of treated animals remains to be determined. However, it may represent the basis for the rapid muscle plasticity and adaptation to aerobic exercise, possibly allowing a reprogramming of muscle cells toward a more oxidative phenotype, through an increased coding efficiency for contractile proteins and genes involved in fatty acid oxidation and mitochondrial biogenesis [39]. This hypothesis could explain the role of PPAR $\beta$ induction after various types of physical training $[9,18,42]$. Finally, our data indicate that, in addition to its beneficial effects on metabolism, PPAR $\beta$ agonists may represent a therapeutic approach for the treatment of age-related muscle atrophy.
Acknowledgments GW0742 was a generous gift from T.M. Willson (GlaxoSmithKline). The CREB antibody was a gift of M. Montminy. We thank E. Lendoye, M. Aupetit, M. Radjkhumar, F. Millot, J. Paput, G. Manfroni and G. Visciano for technical assistance. We thank Dr. Kay-Dietrich Wagner for critical reading of the manuscript. This work was supported by a grant to $\mathrm{PG}$ from the Agence Nationale de la Recherche (ANR-05-PCOD-012). NW has a fellowship from the Fondation de France. The authors have no conflicting financial interest.

Open Access This article is distributed under the terms of the Creative Commons Attribution Noncommercial License which permits any noncommercial use, distribution, and reproduction in any medium, provided the original author(s) and source are credited.

\section{References}

1. Adams GR, Haddad F, Baldwin KM (1999) Time course of changes in markers of myogenesis in overloaded rat skeletal muscles. J Appl Physiol 87:1705-1712

2. Allen DL, Monke SR, Talmadge RJ, Roy RR, Edgerton VR (1995) Plasticity of myonuclear number in hypertrophied and atrophied mammalian skeletal muscle fibers. J Appl Physiol 78:1969-1976

3. Bassel-Duby R, Olson EN (2006) Signaling pathways in skeletal muscle remodeling. Annu Rev Biochem 75:19-37

4. Brack AS, Bildsoe H, Hughes SM (2005) Evidence that satellite cell decrement contributes to preferential decline in nuclear number from large fibres during murine age-related muscle atrophy. J Cell Sci 118:4813-4821

5. Bruusgaard JC, Liestol K, Gundersen K (2006) Distribution of myonuclei and microtubules in live muscle fibers of young, middle-aged, and old mice. J Appl Physiol 100:2024-2030

6. Chambers RL, McDermott JC (1996) Molecular basis of skeletal muscle regeneration. Can J Appl Physiol 21:155-184

7. Degenhardt T, Saramaki A, Malinen M, Rieck M, Vaisanen S, Huotari A, Herzig KH, Muller R, Carlberg C (2007) Three members of the human pyruvate dehydrogenase kinase gene family are direct targets of the peroxisome proliferator-activated receptor beta/delta. J Mol Biol 372:341-355

8. Friday BB, Pavlath GK (2001) A calcineurin- and NFATdependent pathway regulates Myf5 gene expression in skeletal muscle reserve cells. J Cell Sci 114:303-310

9. Fritz T, Kramer DK, Karlsson HK, Galuska D, Engfeldt P, Zierath JR, Krook A (2006) Low-intensity exercise increases skeletal muscle protein expression of PPARdelta and UCP3 in type 2 diabetic patients. Diabetes Metab Res Rev 22:492498

10. Gaudel C, Schwartz C, Giordano C, Abumrad NA, Grimaldi P (2008) Pharmacological activation of PPAR \{beta\} promotes rapid and calcineurin-dependent fiber remodeling and angiogenesis in mouse skeletal muscle. Am J Physiol Endocrinol Metab 295: E297-E304

11. Grounds MD, Garrett KL, Lai MC, Wright WE, Beilharz MW (1992) Identification of skeletal muscle precursor cells in vivo by use of MyoD1 and myogenin probes. Cell Tissue Res 267:99-104

12. Haddad F, Adams GR (2006) Aging-sensitive cellular and molecular mechanisms associated with skeletal muscle hypertrophy. J Appl Physiol 100:1188-1203

13. Hughes SM, Schiaffino S (1999) Control of muscle fibre size: a crucial factor in ageing. Acta Physiol Scand 167:307-312

14. Ishido M, Kami K, Masuhara M (2004) Localization of MyoD, myogenin and cell cycle regulatory factors in hypertrophying rat skeletal muscles. Acta Physiol Scand 180:281-289 
15. Leibowitz MD, Fievet C, Hennuyer N, Peinado-Onsurbe J, Duez H, Bergera J, Cullinan CA, Sparrow CP, Baffic J, Berger GD, Santini C, Marquis RW, Tolman RL, Smith RG, Moller DE, Auwerx J (2000) Activation of PPARdelta alters lipid metabolism in $\mathrm{db} / \mathrm{db}$ mice. FEBS Lett 473:333-336

16. Li P, Akimoto T, Zhang M, Williams RS, Yan Z (2006) Resident stem cells are not required for exercise-induced fiber-type switching and angiogenesis but are necessary for activity-dependent muscle growth. Am J Physiol Cell Physiol 290:C1461-1468

17. Luquet S, Gaudel C, Holst D, Lopez-Soriano J, Jehl-Pietri C, Fredenrich A, Grimaldi PA (2005) Roles of PPAR delta in lipid absorption and metabolism: a new target for the treatment of type 2 diabetes. Biochim Biophys Acta 1740:313-317

18. Luquet S, Lopez-Soriano J, Holst D, Fredenrich A, Melki J, Rassoulzadegan M, Grimaldi PA (2003) Peroxisome proliferatoractivated receptor delta controls muscle development and oxidative capability. Faseb J 17:2299-2301

19. Mauro A (1961) Satellite cell of skeletal muscle fibers. J Biophys Biochem Cytol 9:493-495

20. Miniou P, Tiziano D, Frugier T, Roblot N, Le Meur M, Melki J (1999) Gene targeting restricted to mouse striated muscle lineage. Nucleic Acids Res 27:e27

21. Oliver WR Jr, Shenk JL, Snaith MR, Russell CS, Plunket KD, Bodkin NL, Lewis MC, Winegar DA, Sznaidman ML, Lambert MH, Xu HE, Sternbach DD, Kliewer SA, Hansen BC, Willson TM (2001) A selective peroxisome proliferator-activated receptor delta agonist promotes reverse cholesterol transport. Proc Natl Acad Sci U S A 98:5306-5311

22. Perez-Ruiz A, Gnocchi VF, Zammit PS (2007) Control of Myf5 activation in adult skeletal myonuclei requires ERK signalling. Cell Signal 19:1671-1680

23. Pesant M, Sueur S, Dutartre P, Tallandier M, Grimaldi PA, Rochette L, Connat JL (2006) Peroxisome proliferatoractivated receptor delta (PPARdelta) activation protects $\mathrm{H} 9 \mathrm{c} 2$ cardiomyoblasts from oxidative stress-induced apoptosis. Cardiovasc Res 69:440-449

24. Rantanen J, Hurme T, Lukka R, Heino J, Kalimo H (1995) Satellite cell proliferation and the expression of myogenin and desmin in regenerating skeletal muscle: evidence for two different populations of satellite cells. Lab Invest 72:341-347

25. Robertson TA, Grounds MD, Mitchell CA, Papadimitriou JM (1990) Fusion between myogenic cells in vivo: an ultrastructural study in regenerating murine skeletal muscle. J Struct Biol 105:170-182

26. Robertson TA, Grounds MD, Papadimitriou JM (1992) Elucidation of aspects of murine skeletal muscle regeneration using local and whole body irradiation. J Anat 181(Pt 2):265-276

27. Robertson TA, Papadimitriou JM, Grounds MD (1992) Fusion between a myogenic cell in the satellite cell position and undamaged adult myofibre segments. Experientia 48:394-395

28. Robertson TA, Papadimitriou JM, Grounds MD (1993) Fusion of myogenic cells to the newly sealed region of damaged myofibres in skeletal muscle regeneration. Neuropathol Appl Neurobiol 19:350-358

29. Rosenblatt JD, Yong D, Parry DJ (1994) Satellite cell activity is required for hypertrophy of overloaded adult rat muscle. Muscle Nerve 17:608-613
30. Roy RR, Monke SR, Allen DL, Edgerton VR (1999) Modulation of myonuclear number in functionally overloaded and exercised rat plantaris fibers. J Appl Physiol 87:634-642

31. Sabourin LA, Rudnicki MA (2000) The molecular regulation of myogenesis. Clin Genet 57:16-25

32. Salleo A, La Spada G, Falzea G, Denaro MG, Cicciarello R (1983) Response of satellite cells and muscle fibers to long-term compensatory hypertrophy. J Submicrosc Cytol 15:929-940

33. Schultz E (1989) Satellite cell behavior during skeletal muscle growth and regeneration. Med Sci Sports Exerc 21:S181-186

34. Scicchitano BM, Spath L, Musaro A, Molinaro M, Rosenthal N, Nervi C, Adamo S (2005) Vasopressin-dependent myogenic cell differentiation is mediated by both $\mathrm{Ca} 2+/$ calmodulindependent kinase and calcineurin pathways. Mol Biol Cell 16:3632-3641

35. Smith HK, Maxwell L, Rodgers CD, McKee NH, Plyley MJ (2001) Exercise-enhanced satellite cell proliferation and new myonuclear accretion in rat skeletal muscle. J Appl Physiol 90:1407-1414

36. Sprecher DL, Massien C, Pearce G, Billin AN, Perlstein I, Willson TM, Hassall DG, Ancellin N, Patterson SD, Lobe DC, Johnson TG (2007) Triglyceride:high-density lipoprotein cholesterol effects in healthy subjects administered a peroxisome proliferator activated receptor delta agonist. Arterioscler Thromb Vasc Biol 27:359-365

37. Stockdale FE, Holtzer H (1961) DNA synthesis and myogenesis. Exp Cell Res 24:508-520

38. Sznaidman ML, Haffner CD, Maloney PR, Fivush A, Chao E, Goreham D, Sierra ML, LeGrumelec C, Xu HE, Montana VG, Lambert MH, Willson TM, Oliver WR Jr, Sternbach DD (2003) Novel selective small molecule agonists for peroxisome proliferator-activated receptor delta (PPARdelta) - synthesis and biological activity. Bioorg Med Chem Lett 13:1517-1521

39. Tseng BS, Kasper CE, Edgerton VR (1994) Cytoplasm-tomyonucleus ratios and succinate dehydrogenase activities in adult rat slow and fast muscle fibers. Cell Tissue Res 275:39-49

40. Wagers AJ, Conboy IM (2005) Cellular and molecular signatures of muscle regeneration: current concepts and controversies in adult myogenesis. Cell 122:659-667

41. Wang YX, Lee CH, Tiep S, Yu RT, Ham J, Kang H, Evans RM (2003) Peroxisome-proliferator-activated receptor delta activates fat metabolism to prevent obesity. Cell 113:159-170

42. Watt MJ, Southgate RJ, Holmes AG, Febbraio MA (2004) Suppression of plasma free fatty acids upregulates peroxisome proliferator-activated receptor (PPAR) alpha and delta and PPAR coactivator 1alpha in human skeletal muscle, but not lipid regulatory genes. J Mol Endocrinol 33:533-544

43. Yablonka-Reuveni Z (1995) Development and postnatal regulation of adult myoblasts. Microsc Res Tech 30:366-380

44. Zammit PS, Heslop L, Hudon V, Rosenblatt JD, Tajbakhsh S, Buckingham ME, Beauchamp JR, Partridge TA (2002) Kinetics of myoblast proliferation show that resident satellite cells are competent to fully regenerate skeletal muscle fibers. Exp Cell Res 281:39-49

45. Zhong H, Roy RR, Siengthai B, Edgerton VR (2005) Effects of inactivity on fiber size and myonuclear number in rat soleus muscle. J Appl Physiol 99:1494-1499 